\title{
中国鸟类亚种新记录一一黑冠黄塊
}

蒋爱伍 ${ }^{1}$, 盘宏权 ${ }^{2}$, 陆 舟 $^{3}$, 刘迺发 ${ }^{1, *}$

1. 兰州大学 生命科学学院, 甘肃 兰州 730000; 2. 广西百色市中级人民法院, 广西 百色 533000; 3. 广西大学 动物科学技术学院, 南宁 530005

摘要: 2010 年 12 月和 2011 年 4 月, 分别在广西西北部百色市右江区和靖西县古龙山自然保护区拍摄和观察到黑冠黄鹎 (Pycnonotus flaviventris) 的 johnsoni 亚种。其喉部为红色, 与中国其他记录亚种区别明显, 属中国鸟类亚种的新记录。该文亦 初步讨论了该亚种的分类和分布。

关键词: 黑冠黄軼； 新记录; 亚种; 广西

中图分类号：Q959.7+39 文献标志码：A 文章编号：0254-5853-(2013)01-0053-02

\section{A new record of the bird subspecies Black-crested Bulbul (Pycnonotus flaviventris johnsoni) in China}

\author{
Ai-Wu JIANG ${ }^{1}$, Hong-Quan PAN ${ }^{2}$, Zhou LU ${ }^{3}$, Nai-Fa LIU ${ }^{1, *}$ \\ 1. School of Life Sciences, Lanzhou University, Lanzhou 730000, China； 2. Baise Intermediate People's Court, Baise 530000, China \\ 3. College of Animal Sciences and Technology, Nanning 530005, China
}

\begin{abstract}
Several Black-crested Bulbul (Pycnonotus flaviventris) with red throats were observed and photographed in December 2010 and April 2011 in the Youjiang District (N23 $54^{\prime}$, E06 $36^{\prime}$, altitude $179 \mathrm{~m}$ ) and Jingxi County(N22 $59^{\prime}$, E1 $06^{\circ} 40^{\prime}$, altitude 354 $\mathrm{m})$ of Baise city, northwestern Guangxi, in southern China. These individuals belong to subspecies johnsoni, recorded previously in central and southeastern Thailand as well as the southern Indochina Region. This sighting provides a new record of the subspecies within China, warranting a discussion on the classification and distribution of Pycnonotus flaviventris.
\end{abstract}

Keywords: Pycnonotus flaviventris; new bird record; subspecies; Guangxi

2010 年 12 月在广西百色市右江区 $\left(\mathrm{N} 23^{\circ} 54^{\prime}\right.$, $\mathrm{E} 106^{\circ} 36^{\prime}$, 海拔 $\left.179 \mathrm{~m}\right)$ 附近观察和拍摄到黑冠黄鹎 (Pycnonotus flaviventris), 但其喉部为红色, 与国内 两个记录亚种区别明显。2011 年 4 月, 在百色市靖 西县的古龙山自然保护区 $\left(\mathrm{N} 22^{\circ} 59^{\prime}, \mathrm{E} 106^{\circ} 40^{\prime}\right.$, 海拔 $354 \mathrm{~m})$ 也观察到具有该特征的黑冠黄鹎活动。经查 阅文献鉴定为中国鸟类亚种新记录——黑冠黄鹎 的 johnsoni 亚种。

\section{1 鉴定特征}

黑冠黄唡为中等体型的雀形目鸟类，隶属于䅉 科(Pycnonotidae)軠属。此次在广西百色市所观察和 拍摄到的鸟类上体呈橄榄黄绿色, 下体呈纯橄榄黄 色。整个头部呈黑色, 具有明显的直立黑色羽冠。 但喉部为红色, 与广西其他地区的黑冠黄鸼明显不
同(图 1)。

\section{2 栖息地及行为}

黑冠黄鸼 johnsoni 亚种的发现地点为位于广西 西北部云贵高原边缘右江河谷地带的百色市, 西部 与我国云南省相连, 南与越南接壤。百色属亚热带 季风气候, 年平均气温 $22.2^{\circ} \mathrm{C}$ 。降雨量为 1000 $1200 \mathrm{~mm}$, 主要集中在每年的 4-9 月。该黑冠黄 軼活动于当地群众的菜园附近, 周围的天然植被为 具有热带性质的常绿落叶阔叶混交林。由于人为破 坏, 多数地方已经被种植马尾松 (Pinus massoniana) 和桉树 (Eucalyptus spp.), 仅在沟谷和山顶保留少量 天然植被。在右江区黑冠黄唡的 johnsoni 亚种单个 或成对活动。另一发现地点古龙山自然保护区位于 广西百色市靖西县境内, 与越南北部的直线距离

收稿日期：2012-12-21；接受日期：2013-01-14

基金项目: 国家自然科学基金 (31172123)

“通信作者 (Corresponding author), E-mail: naifaliu@sohu.com 


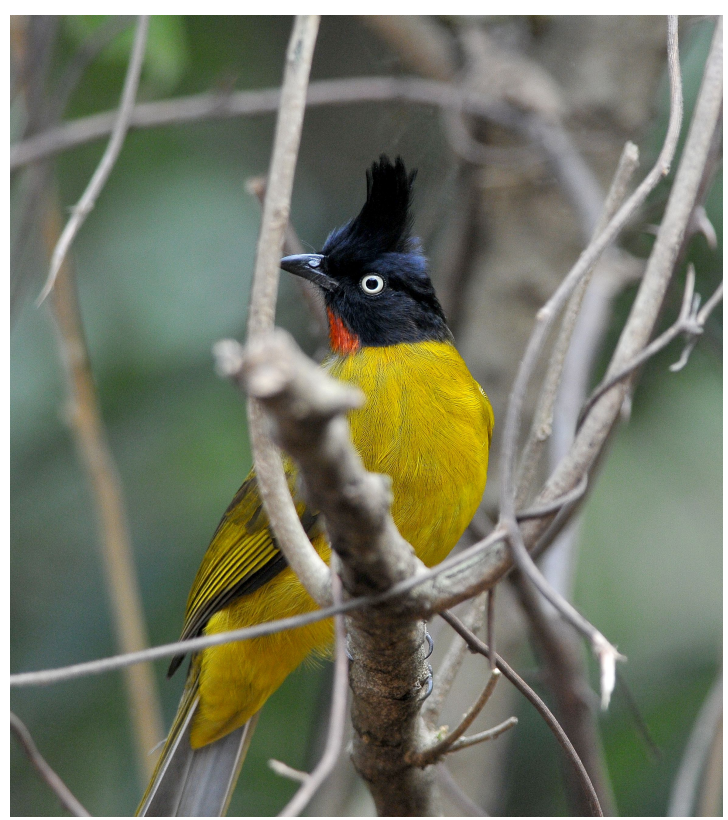

图 1 黑冠黄軠 johnsoni 亚种 (盘宏权 摄)

Figure 1 Black-crested Bulbul (Pycnonotus flaviventris johnsoni) (Photo by PAN Hong-Quan)

$10 \mathrm{~km}$ 。当时, 共观察到 10 余只黑冠黄鹎活动, 喉 部红色的个体为 $2 \sim 3$ 只。古龙山为典型的石灰岩 地貌, 天然植被为季节性山地雨林。由于人为影响, 大部分已被次生林和灌丛代替。

与黑冠黄齁 johnsoni 亚种一起活动的鸟类为当 地次生林和灌丛生境的常见种, 如红耳鹎 (Pycnonotus jocosus)、白喉红慰塊(P. aurigaster)、长 尾缝叶莺 (Orthotomus sutorius)、暗绿绣眼鸟 (Zosterops japonica) 和大山雀(Parus major)等。黑冠 黄鹎的 vantynei 亚种也见在附近活动。经观察, 此 次记录的 johnsoni 亚种羽色较鲜亮, 羽毛完整, 飞 翔及受食活动自如, 而且在两个距离较远的地点均 观察到多个个体活动, 记录地点也与这一亚种的原 区较为接近, 因此, 可以排除笼养放生鸟类的可能。

\section{参考文献:}

Clements JF. 2007. The Clements Checklist of the Birds of the World. New York: Cornell University Press

de Schauensee RM. 1946. On Siamese Birds . Proceedings of the Academy of Natural Sciences of Philadelphia, 98: 1-82.

del Hoyo J, Elliott A, Christie D. 2005. Handbook of the Birds of the World, vol. 10: Cuckoo-Shrikes to Thrushes. Lynx Edicions, Barcelona, Spain. Dickinson EC, Dekker R. 2002. Systematic notes on Asian birds. 25. A preliminary review of the Pycnonotidae. Zoologische Verhandelingen, 340(27): 93-114

Gill F, Donsker D. 2012. IOC World Bird List (v3. 1) Available at http://www.worldbirdnames.org/ [Accessed Dec 12, 2012].

MacKinnon J, Phillipps K. 2000. A Field Guide to the Birds of China.

\section{3 讨 论}

黑冠黄䅉广泛分布于印度、东南亚、大巽他群 岛和我国的广西、云南及西藏等省区 (MacKinnon \& Phillipps, 2000; Zheng, 2011)。由于存在多种色 型, 黑冠黄鹐的分类比较复杂, 分类地位也出现多 次变动 (Dickinson \& Dekker, 2002)。有学者将其列 为一种并包括 12 亚种 (Clements, 2007)。但多数学 者根据羽冠的有无、喉部和虹膜的颜色以及地理分 布等将黑冠黄䅉分为 5 个独立的种 (del Hoyo et al, 2005; Gill \& Donsker, 2012)。红宝石喉鹎 (Pycnonotus dispar)和火焰喉鹎(Pycnonotus gularis) 喉部发红且羽冠较短, 分布于斯里兰卡的黑顶黄鹎 (Black-capped Bulbul Pycnonotus melanicterus)和婆 罗洲的特有种婆罗洲䡚(Pycnonotus montis) 喉部发 黄且羽冠较低或近似无，而另外 8 个亚种则隶属分 布于中国南方和中南半岛的黑冠黄䅉。由于黑冠黄 軼的原名 Pycnonotus melanicterus 已作为黑顶黄軼鸟 的学名, 因此, 根据命名优先原则将黑冠黄鹎的学 名定为 Pycnonotus flaviventris。

黑冠黄鹎在我国记录分布有 2 个亚种: 指名亚 种分布于云南西部; vantynei 亚种见于云南南部及 广西等地 (Zheng, 2011)。在广西, 黑冠黄鹎主要见 于广西西部地区, 为留鸟 (Zhou et al, 2011)。黑冠 黄唡的 8 个亚种均具有高而直的黑色羽冠, 但只有 johnsoni 亚种喉部红色，与其他亚种区别明显 (Robson, 2005)。喉部红色有时也会被视为黑冠黄殅 的一种色型(de Schauensee, 1946), 因此这一亚种的 分类可能值得讨论。johnsoni 亚种原记录分布于泰 国高原南部、老挝南部、柬埔寨和越南等地 (Clements，2007)。此次在广西百色市记录到 johnsoni 亚种表明它的分布区已经向北延伸到中国 南部，且与 vantynei 亚种同域分布，这对今后进一 步讨论黑冠黄唡的分类及演化具有一定意义。

Boston: Oxford University Press, USA.

Robson C. 2005. New Holland Field Guide to the Birds of South-East Asia: Thailand, Peninsular Malaysia, Singapore, Vietnam, Cambodia, Laos, Myanmar. London: New Holland Publishers.

Zheng GM. 2011. A Checklist on the Classification and Distribution of the Birds of China . 2nd ed. Beijing: Science Press. [郑光美. 2011. 中国鸟类 分类与分布名录. 2 版. 北京: 科学出版社.]

Zhou F, Jiang AW, Mo YM, Wei ZY, Wang B. 2011. The Checklist of Terrestrial Vertebrate Distribution in Guangxi. Beijing: Chinese Forestry Press. [周放，蒋爱伍，莫运明，韦振逸，王波. 2011. 广西陆栖脊椎动物 分布名录. 北京: 中国林业出版社.] 